\title{
The impact of information provision to parents: Experimental evidence on student outcomes
}

Citation for published version (APA):

Maldonado, J. E., \& De Witte, K. (2021). The impact of information provision to parents: Experimental evidence on student outcomes. Journal of Behavioral and Experimental Finance, 31, [100548]. https://doi.org/10.1016/j.jbef.2021.100548

Document status and date:

Published: 01/09/2021

DOI:

10.1016/j.jbef.2021.100548

Document Version:

Publisher's PDF, also known as Version of record

Document license:

Taverne

Please check the document version of this publication:

- A submitted manuscript is the version of the article upon submission and before peer-review. There can be important differences between the submitted version and the official published version of record.

People interested in the research are advised to contact the author for the final version of the publication, or visit the DOI to the publisher's website.

- The final author version and the galley proof are versions of the publication after peer review.

- The final published version features the final layout of the paper including the volume, issue and page numbers.

Link to publication

\footnotetext{
General rights rights.

- You may freely distribute the URL identifying the publication in the public portal. please follow below link for the End User Agreement:

www.umlib.nl/taverne-license

Take down policy

If you believe that this document breaches copyright please contact us at:

repository@maastrichtuniversity.nl

providing details and we will investigate your claim.
}

Copyright and moral rights for the publications made accessible in the public portal are retained by the authors and/or other copyright owners and it is a condition of accessing publications that users recognise and abide by the legal requirements associated with these

- Users may download and print one copy of any publication from the public portal for the purpose of private study or research.

- You may not further distribute the material or use it for any profit-making activity or commercial gain

If the publication is distributed under the terms of Article $25 \mathrm{fa}$ of the Dutch Copyright Act, indicated by the "Taverne" license above, 
Full length article

\title{
The impact of information provision to parents: Experimental evidence on student outcomes
}

\author{
Joana Elisa Maldonado ${ }^{\mathrm{a}, *}$, Kristof De Witte ${ }^{\mathrm{a}, \mathrm{b}}$ \\ a Leuven Economics of Education Research (LEER), KU Leuven, Naamsestraat 69, Leuven, 3000, Belgium \\ ${ }^{\mathrm{b}}$ United Nations University - Maastricht Economic and Social Research Institute on Innovation and Technology (UNU-MERIT), Boschstraat \\ 24, Maastricht, 6211 AX, The Netherlands
}

\section{A R T I C L E I N F O}

\section{Article history:}

Received 16 June 2020

Received in revised form 2 July 2021

Accepted 12 July 2021

Available online 16 July 2021

\section{JEL classification:}

C93

I21

D83

A21

G53

Keywords:

Parental involvement

Information

Financial literacy

Randomised controlled trial

\begin{abstract}
A B S T R A C T
Targeted parental involvement is increasingly employed to activate parents to use their supporting role to enhance learning effects of students. Given the low cost, one popular measure is information provision to parents. However, the evidence on such measures remains limited. This study provides causal evidence on the effects of information provision to parents in a financial education course where parental involvement was stimulated. Based on a randomised controlled trial with 1253 students from grade 8 and 9 in Flanders, we identify the effects of the classroom intervention separately from parental involvement prompted in homework and the provision of subject-specific information to parents on students' learning outcomes. The estimates reveal that, overall, the treatment effectively increases financial knowledge and skills. However, despite its popularity in schools, the value added of prompting parental involvement and providing parents information is not significant overall, but only for financial skills.
\end{abstract}

(c) 2021 Elsevier B.V. All rights reserved.

\section{Introduction}

A child's education is determined by the combination of parental and societal investments. However, insufficient information, complexity of tasks and delayed gratification could cause parents to underinvest in the academic development of their children (York et al., 2019). Targeted parental involvement measures are therefore increasingly used to boost parental effort with the goal to enhance student performance. If low levels of parental effort are due to an information bias about the relevance of parents' role and a lack of information about useful ways to get involved, provision of information to parents could lead to adjustments of parental efforts to for society optimal levels.

Information provision to parents is a scalable low-cost intervention that is commonly used in schools. Recent economic literature demonstrates positive effects of reporting students' performance and behaviour to parents. This type of information provision is shown to positively affect student achievement and

\footnotetext{
This study is registered in the AEA RCT Registry under the identifier AEARCTR-0004990.

* Corresponding author.

E-mail addresses: joanaelisa.maldonado@kuleuven.be (J.E. Maldonado), kristof.dewitte@kuleuven.be (K. De Witte).
}

behavioural outcomes (Berlinski et al., 2021; Bergman and Chan, 2021). In addition, these interventions appear to reduce parents' information biases about their children's performance (Bergman, 2021; Dizon-Ross, 2019). Furthermore, Mayer et al. (2019) show that informing parents of pre-school children about the importance of their involvement increases parents' engagement with their children. In particular, personalised and differentiated messages to parents have proven more effective than a general programme in this context (Doss et al., 2019).

Nevertheless, the evidence on providing parents subjectspecific information remains limited. This study provides experimental evidence on the effects of giving parents subjectspecific information on students' learning outcomes in a financial education course.

Financial education lends itself as a subject to evaluate parental involvement interventions. Although increased financial literacy does not automatically result in better consumer choices (De Beckker et al., 2021), financial literacy is considered of increasing importance in today's quickly developing market economies, where the management of personal finances determines earnings and assets. Yet, many students lack financial knowledge (OECD, 2017; Lusardi et al., 2010; De Beckker et al., 2019), such that the topic is increasingly included in education curricula. Experiments in secondary schools with randomised 
treatment show positive effects of financial education courses on financial knowledge and financial behaviour in developed economies (Becchetti et al., 2013; Bover et al., 2018; Compen et al., 2021; Iterbeke et al., 2020, 2021; Lührmann et al., 2018). ${ }^{1}$ More in general, recent meta-analyses of experimental studies demonstrate significant positive effects of financial education interventions (Kaiser and Menkhoff, 2020; Kaiser et al., 2020). Correlational studies suggest a link between the financial literacy of parents and their children (e.g. Dohmen et al., 2012; Webley and Nyhus, 2006), and indicate that discussing financial topics with parents is associated with higher financial literacy of children (Hanson and Olson, 2018; Moreno-Herrero et al., 2018). Experimental evidence shows that financial education at school can increase family communication about financial topics (Bover et al., 2018). Financial education interventions at school with a parental involvement component have resulted in positive overall effects for students (Bruhn et al., 2016; Sherraden et al., 2011; Maldonado et al., 2021). Maldonado et al. (2021) identify the value added of the parental involvement element, which appears to matter for disadvantaged students in the behavioural dimension.

Educating parents about their important role in the financial socialisation of their children might improve students' financial literacy and financial behaviour (Bucciol and Veronesi, 2014; Shim et al., 2015). Yet, to our knowledge, information provision to parents has not been evaluated in the context of financial education. In the interventions of Bruhn et al. (2016) and Sherraden et al. (2011), parents received information at a parent event. However, these studies do not identify the effect of the parent events separately from the overall effect of the financial education class. Studies on the provision of educational information to parents in other subjects are largely limited on interventions in early childhood (Doss et al., 2019; York et al., 2019). These differ widely from the specialised subject content in high school and parent-child-relationships in teenage years. Experiments in higher grades considered information on parental support without subject-specific content (Avvisati et al., 2014; Bergman, 2021). Heddy and Sinatra (2017) and Rozek et al. (2017) evaluate information for parents specific to science and mathematics education, but use very small samples, resulting in low power and low external validity of the results.

This paper is the first to examine the impact of providing subject-specific content information on learning outcomes in financial education. We test the effectiveness of stimulating parental involvement through cost-effective and scalable measures, that is information and homework, and the dynamic complementarities thereof. Based on causal evidence from a randomised controlled trial with 1253 students from grade 8 and 9 in Flanders, we evaluate the information intervention in a financial education course on saving and investing with a parental involvement prompt. With three different treatment groups (next to a control group), we separately identify the effects of a classroom intervention without stimulated parental involvement, parental involvement prompted in homework and the provision of information about the subject to parents. Although the research

\footnotetext{
1 As the present study is part of a larger research project on how financial literacy can be effectively introduced in Flemish secondary schools, despite different research questions, implementation dates, hypotheses, and underlying course materials, some other studies share the context of secondary schools in Flanders. For example, using a RCT, Iterbeke et al. (2020) evaluate the impact of ability matching and differentiated instruction in a course on payment methods. In a similar setting, Maldonado et al. (2021) consider the impact of parental involvement in homework. Using RCTs, Compen et al. (2021) test the effects of online teacher professional development and Iterbeke et al. (2021) evaluate the effectiveness of adaptive instruction, exploiting the same control group used in the present paper.
}

team was responsible for the design and evaluation phase of the experiment, the practical implementation of the course materials was in the hands of teachers. This makes sure that our estimates are not necessarily upper bound estimates of an intervention with perfect implementation. In other words, this study design simulates the implementation of interventions in the real world, with the disadvantage of a lower degree of control over compliance with the treatment and the tests. Testing scalable interventions in realistic conditions is important to evaluate the effects of potential policy interventions.

To reduce the imbalances in student characteristics at baseline, which occurred due to attrition after randomisation, we apply difference-in-differences estimation and coarsened exact matching of students of each treatment group to the control group. The results show that, overall, the treatment effectively increases students' financial literacy, in both dimensions of financial knowledge and simulated financial skills. While the assignment to treatment with information combined with the class and prompting parental involvement in homework leads to significant positive effects on all outcomes compared to the control group, the value added of information provision is not significant on financial literacy and financial knowledge. There is, however, a significant positive effect of information provision to parents on student scores on aspects of the course topic relating to financial skills. We do not find strong heterogeneous treatment effects based on student characteristics.

The paper is structured as follows. Section 2 introduces the experimental design and Section 3 provides details about the intervention. Section 4 describes the sample and Section 5 explains the methodology used. In Section 6, the results are presented, followed by a discussion and conclusion in Section 7.

\section{Experimental design}

To separately identify the effects of information provision to parents, the parental involvement measure and the classroom intervention, we conducted a randomised controlled trial with four experimental groups. The experiment was run in the Flemish region of Belgium with students in grade 8 and 9, i.e. the second and third year of secondary education in Belgium. An open call was launched via the Belgian financial literacy agency (Wikifin) and resulted in the recruitment of 44 schools.

Fig. 1 shows the timing of the different phases of the experiment. The experiment took place between August and December 2018 and was conducted in two consecutive waves with identical interventions. At registration, schools chose to implement the intervention in October or November. In this way, schools signing up for the second wave could be randomised to the control group, i.e. be assigned a post-test in October, while still receiving the teaching material in November as incentive to complete all tests. After the registration, the schools were randomised to the experimental groups. To avoid spill-over effects between teachers and classes, the randomisation was done at school level. Before the intervention, students in all experimental groups completed a pre-test. After the intervention, students in the treatment groups completed a post-test. Schools in the control group completed the post-test several weeks after the pre-test, before receiving any teaching material.

Fig. 2 provides an overview of the four experimental groups. Students in the control group did not receive any treatment. Since financial literacy was, at the time of the intervention, not part of the curriculum in secondary schools, it can be excluded that the control group received other similar classes. Students in all treatment groups were assigned to a 4-hour classroom intervention. Students in treatment group 1 (labelled as 'Class') were assigned to complete a homework before the class. Students 


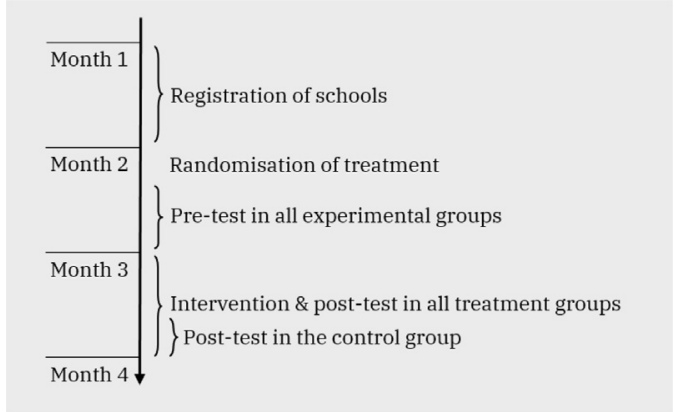

Fig. 1. Time line.

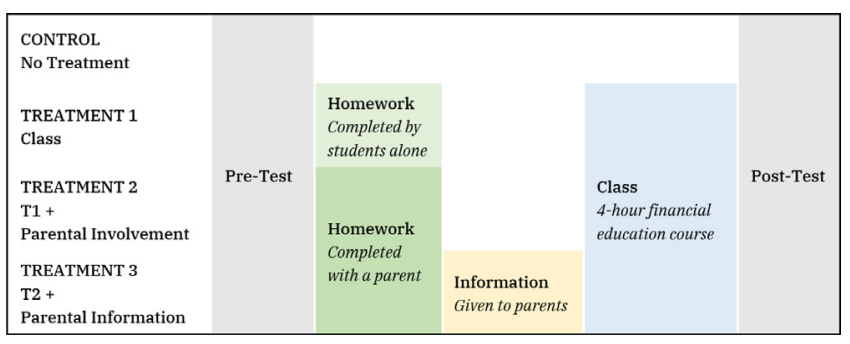

Fig. 2. Experimental design.

in treatment groups 2 (labelled as 'T1 + Parental Involvement') and 3 (labelled as 'T2 + Parental Information') were assigned the same homework but with additional stimulation of parental involvement. In addition, students in treatment group 3 were assigned to receive an information brochure for their parents. The timing of the homework and the information brochure before the classroom intervention intended to maximise the time parents would have to get involved during the classroom intervention.

Students in all experimental groups completed the same pretest before the intervention and the same post-test at the end of the classroom intervention. All tests were administered electronically, via a link provided to the teacher. Students completed the tests under supervision of the teacher in the classroom, working individually on computers. The pre-test asked for some background characteristics of the students and attitude questions about financial topics, saving and investing. Moreover, the pretest measured the financial literacy level of students with nine questions about the course topic, of which six were knowledge questions and three questions simulated financial skills. The latter measured objectively assessable skills by asking students to take a decision in a fictional scenario related to the course topic. In particular, the skill questions assessed the ability to identify fraud, to establish a saving strategy and keep money in a safe way. Three knowledge questions in the test were based on the commonly used financial literacy questions by Lusardi et al. (2010). Other questions were inspired by the PISA assessments of financial literacy, which are designed for a similar population of 15-year old students (OECD, 2014, 2017), and previously used in financial education experiments (Iterbeke et al., 2020). ${ }^{2}$ The remainder of the questions was designed to capture the content covered in this specific intervention. The post-test corresponded to the pretest with equivalent, slightly modified questions. The financial

\footnotetext{
2 Overall, the set of questions used in the present paper were similar to Iterbeke et al. (2020) and Compen et al. (2021). The questions were face validated by two experienced teachers. Although the specificity of the pre- and post-treatment questions results in a low internal consistency $(\alpha=0.43$ and 0.56 , respectively), the Pearson Product Moment correlation was reported to amount to 0.10 or higher, suggesting a fair to good discrimination. The item difficulty varies between 0.31 and 0.76 .
}

literacy score was based on a modified version of the set of six knowledge and three skill questions from the pre-test. The tests were validated previous to the intervention by trial use in two test schools. The test questions are provided in appendix D.1.

Parents of students in all three treatment groups were also given a survey. Teachers were assigned to give this survey to parents after the student completed the pre-test at school. The questionnaire for parents measured some background characteristics, as well as attitudes, and contained an assessment on six general financial literacy questions. Appendix D.2 shows the parent questionnaire.

\section{Intervention}

It is well-established that, next to the school, parents represent an important channel of financial socialisation in childhood. Being taught by parents in childhood about budgeting and saving was shown to be associated with $14 \%$ higher financial literacy (Grohmann et al., 2015) and increased saving as adults (Bucciol and Veronesi, 2014). Family communication patterns have been linked to the financial knowledge of students, with a positive influence of a strong conversation orientation (Hanson and Olson, 2018). Similarly, discussing financial topics with parents has been found to be associated with higher financial literacy scores on the PISA assessment of 15-year old students (Moreno-Herrero et al., 2018). Many studies find parents to be the primary source of information on financial topics (Van Campenhout, 2015).

Therefore, involving parents in financial education interventions in schools as well as providing parents information has been suggested as a tool to increase financial literacy of students (Moreno-Herrero et al., 2018; Van Campenhout, 2015). In particular, measures to encourage family interaction on financial matters, such as homework, have been named as promising tools in financial education of young adults (Hanson and Olson, 2018). In addition, many studies conclude that educating parents about their important role in the financial socialisation of their children could contribute to improving students' financial literacy and behaviour (Bucciol and Veronesi, 2014; Shim et al., 2015). It is therefore of interest to test the effectiveness of stimulating parental involvement through cost-effective and scalable measures, such as homework and information, and the dynamic complementarities thereof in the framework of a classroom intervention. Given the positive correlational evidence, we expect the treatment of homework and information, which both prompt parental involvement, to increase the financial literacy scores at the end of the complementary classroom intervention.

In the following, we describe the three elements of the intervention in detail: the information intervention, the parental involvement measure and the classroom intervention.

\subsection{Information intervention}

Students in this third 'Parental Information' treatment group (labelled as 'T2 + Parental Information') were assigned to receive an information brochure for their parents before the start of the classroom intervention. Teachers could choose to give this 4-pager as hard-copy or digital document to parents via the students. The brochure provided information in four categories. First, the brochure introduced parents to the relevance of financial education for their child, illustrated with realistic examples about the importance of financial literacy. Second, the brochure presented the topics that would be covered in the financial education course. Third, the brochure suggested practical tips on how parents can support the financial education of their children, with concrete examples from a family's everyday life. Finally, 
the brochure included a list of websites with further information about financial literacy and the different topics covered in the course. Appendix C.1 outlines the contents of the information brochure for parents.

The brochure aimed at reducing a lack of information among parents to increase parental involvement in financial education. Assuming that parents are getting involved in their children's education at a sub-optimal level for children and society, information about the relevance of parental involvement could increase awareness among parents about their important role and provide parents with the required motivation to increase their involvement (Bucciol and Veronesi, 2014; Shim et al., 2015). Practical instructions about how parents can get more involved could enable parents to translate a motivation into actual involvement. Given that many adults lack basic financial literacy themselves (OECD, 2016), the brochure was also intended to increase parents' self-confidence in supporting their children's financial education. In particular, it made explicit that many actions for increasing children's financial literacy can easily be integrated in the family's everyday life without requiring specific knowledge.

The brochure fulfilled the key constraints that, according to Lieberman et al. (2014) need to be fulfilled in order to generate private activism with an information intervention for parents. The brochure was written in plain language, such that it could easily be understood. Given that parents answer, on average, only 3 out of 6 financial literacy questions correctly in the parent survey before the intervention, the brochure is likely to provide parents with new information that allows an updating of priors. Parents in the sample rate the importance of financial literacy for their child on average 4.3 on a 5-point-Likert scale, showing that they prioritise the subject. The brochure clearly established parents' responsibility to act on this subject, since financial education largely takes place in a child's home environment. With many examples on how to implement financial education in daily life, the brochure made parents aware of possible actions. These examples related to simple tasks that do not require specific skills or knowledge, ensuring that parents have the necessary skills to take action. To ensure self-efficacy, the brochure emphasised that every parent can improve financial education with these simple measures without specific skills or knowledge. Finally, in line with Lieberman et al. (2014), the brochure highlighted the impact that the parental actions can have, i.e. for their children's financial literacy and the relevance of early practice for the future.

As non-compliance on a second parent questionnaire, which teachers were supposed to give parents after the classroom intervention, was extremely high, with only $17 \%$ of parents in the information treatment group completing the survey, it could not be verified if parents received and read the information brochure. This non-compliance can be driven by both non-compliance of teachers and non-compliance by parents. The analysis is therefore strictly limited to the intention-to-treat, which reflects a realistic treatment effect.

\subsection{Parental involvement intervention}

In order to provide parents a concrete opportunity to experience an example of parental involvement, a well-designed parental involvement measure was added at the start of the intervention for students in the second and third treatment groups, i.e. 'T1 + Parental Involvement' and 'T2 + Parental Information'. Homework is a simple measure to prompt parental involvement with low costs and little organisational effort for teachers and schools.

Therefore, a preparatory homework was assigned before the classroom intervention, which stimulated parental involvement.
The homework consisted of a digital assignment given in the form of a handout with instructions and a link to the online assignment. Online, students completed a quiz of six questions, of which one on saving attitude and five on knowledge based on a short video about the course topic of saving and investing. The last question instructed students to use an online savings calculator tool in order to find the correct answer. Appendix C.2 shows an outline of the homework assignment.

Two elements in the homework prompted students to complete the homework together with a parent. First, the instructions in the handout and the online environment clearly asked the student to complete the homework together with a parent. Second, each question of the quiz contained lines for discussion that incentivised students to initiate a discussion and exchange ideas with their parent in order to solve the question. From the parent, these discussion questions did not require any specific preknowledge as all necessary information was provided via links that families could use if parents did not know the correct solutions. As it was not possible to observe the implementation of the homework in the home of students, actual parental involvement could not be measured. We therefore measure the intention-totreat effect of stimulating parental involvement, which reflects a realistic effect of implementing parental involvement in schools.

To distinguish the effects of stimulating parental involvement, students in all treatment groups were assigned homework before the classroom intervention, but students in the 'Class' treatment group were assigned a standard homework without stimulation of parental involvement. Except for the parental involvement prompt, the homework in the 'Class' treatment group was identical to the homework in the 'T1 + Parental Involvement' and 'T2 + Parental Information' treatment groups, with the same information provided and the same questions asked. In all treatment groups, the homework was assigned by the teacher as preparation for the class. While it was not graded, teachers were instructed to emphasise the importance of the homework for the completion of the following class. Students could see their result of the quiz at the end of the homework, but teachers did not receive these scores. However, homework is, in general, perceived as mandatory by students and parents in Flemish schools. As the quiz was completed digitally, we could collect students' homework scores for the research.

\subsection{Classroom intervention}

Students in all three treatment groups received an identical classroom intervention in the form of a digital adaptive learning path on saving and investing. The intervention was highly standardised, since students completed the fully computer-based course independently in groups of two with a minimum of teacher intervention. The class had a duration of four class periods that could be taught in one block or split by teachers in two or four blocks.

Before the beginning of the class, students were ranked by the teacher according to their mathematics grades of the last semester. Following this ranking, students were matched in teams of two students of similar ability. At the start of the class, the assigned teams of two students completed together a digital quiz. As this type of group formation was used in all treatment arms, any social interaction effects resulting from the ability matching should be equally distributed in the three treatment groups. For the remainder of the class, students followed a learning path at one of three ability levels according to their quiz result. All three learning paths had identical learning goals and covered the same content in a digital learning environment provided on a website. The path for the weakest students proceeded at a lower learning speed than the average path, with additional explanations and simplified exercises. The path for the strongest students had at a higher learning speed with less explanations and more challenging exercises. 
Table 1

Descriptive statistics.

\begin{tabular}{|c|c|c|c|c|c|c|c|c|}
\hline & \multicolumn{2}{|c|}{$\begin{array}{l}\text { Control } \\
\text { No treatment }\end{array}$} & \multicolumn{2}{|c|}{$\begin{array}{l}\text { Treatment } 1 \\
\text { Class }\end{array}$} & \multicolumn{2}{|c|}{$\begin{array}{l}\text { Treatment } 2 \\
T 1+\text { Parental Involvement }\end{array}$} & \multicolumn{2}{|c|}{$\begin{array}{l}\text { Treatment } 3 \\
T 2+\text { Parental Information }\end{array}$} \\
\hline Number of students & 305 & & 418 & & 209 & & 321 & \\
\hline Number of schools & 9 & & 10 & & 4 & & 5 & \\
\hline Private schools & $55.56 \%$ & & $80 \%$ & & $100 \%$ & & $80 \%$ & \\
\hline Academic & \multicolumn{2}{|l|}{$94.75 \%$} & \multicolumn{2}{|l|}{$51.2 \%$} & \multicolumn{2}{|l|}{$90.43 \%$} & \multicolumn{2}{|l|}{$64.18 \%$} \\
\hline Technical & \multicolumn{2}{|l|}{$5.25 \%$} & \multicolumn{2}{|l|}{$35.17 \%$} & \multicolumn{2}{|l|}{$9.57 \%$} & \multicolumn{2}{|l|}{$29.91 \%$} \\
\hline Vocational & \multicolumn{2}{|l|}{$0 \%$} & \multicolumn{2}{|l|}{$13.64 \%$} & \multicolumn{2}{|l|}{$0 \%$} & \multicolumn{2}{|l|}{$5.92 \%$} \\
\hline \multicolumn{9}{|l|}{ Student characteristics } \\
\hline Age & 13.42 & $(0.645)$ & 13.72 & $(0.870)$ & 13.74 & $(0.803)$ & 13.47 & $(0.652)$ \\
\hline Female & 0.580 & $(0.494)$ & 0.447 & $(0.498)$ & 0.522 & $(0.501)$ & 0.483 & $(0.500)$ \\
\hline Language Grade & 3.925 & $(0.818)$ & $3.656^{*}$ & $(0.877)$ & 3.024 & $(1.242)$ & $3.377^{* *}$ & $(0.951)$ \\
\hline Mathematics grade & 3.682 & (1.033) & $3.261^{* *}$ & (1.139) & 3.081 & (1.333) & 3.464 & (1.089) \\
\hline Socioeconomic status & 3.049 & $(0.918)$ & $2.773^{* * *}$ & $(1.054)$ & $3.330^{* *}$ & $(0.905)$ & 2.869 & $(1.038)$ \\
\hline Dutch & 0.908 & $(0.289)$ & 0.837 & $(0.370)$ & $0.416^{*}$ & $(0.494)$ & 0.816 & $(0.388)$ \\
\hline Saving preference & 59.64 & $(20.43)$ & 58.86 & $(20.12)$ & 60.08 & $(20.72)$ & 61.27 & $(22.02)$ \\
\hline Importance of saving & 4.285 & $(0.946)$ & 4.172 & $(1.003)$ & 4.163 & $(1.093)$ & 4.184 & $(0.946)$ \\
\hline Self-assessment & 3.420 & $(1.010)$ & 3.366 & $(0.976)$ & 3.364 & $(1.048)$ & 3.405 & $(1.027)$ \\
\hline Importance Fin. Literacy & 4.223 & $(0.736)$ & 4.112 & $(0.755)$ & 4.091 & $(0.718)$ & 4.069 & $(0.738)$ \\
\hline Family communication & 3.256 & $(1.121)$ & $2.931^{* * *}$ & $(1.180)$ & $2.885^{* *}$ & $(1.146)$ & $2.910^{* * *}$ & $(1.176)$ \\
\hline \multicolumn{9}{|l|}{ Pre-Test } \\
\hline Financial literacy $(/ 9)$ & 4.689 & $(1.666)$ & $4.115^{*}$ & $(1.877)$ & 4.282 & $(1.757)$ & $3.960^{* * *}$ & $(1.838)$ \\
\hline Financial knowledge $(/ 6)$ & 2.833 & $(1.231)$ & 2.600 & $(1.305)$ & 2.847 & $(1.183)$ & 2.530 & $(1.299)$ \\
\hline Financial Skills $(/ 3)$ & 1.856 & $(0.931)$ & $1.514^{* *}$ & $(0.992)$ & $1.435^{* *}$ & $(1.032)$ & $1.430^{* * *}$ & $(0.976)$ \\
\hline \multicolumn{9}{|l|}{ Post-test } \\
\hline Financial literacy $(/ 9)$ & 4.905 & $(1.862)$ & 5.122 & $(2.237)$ & 5.364 & $(2.067)$ & 5.168 & $(1.974)$ \\
\hline Financial knowledge $(/ 6)$ & 3.138 & $(1.358)$ & 3.548 & (1.577) & $3.871^{* * *}$ & $(1.434)$ & $3.551^{*}$ & $(1.366)$ \\
\hline Financial skills $(/ 3)$ & 1.767 & $(0.904)$ & 1.574 & $(0.977)$ & $1.493^{* *}$ & $(1.024)$ & 1.617 & $(0.948)$ \\
\hline Observations & 1253 & & & & & & & \\
\hline
\end{tabular}

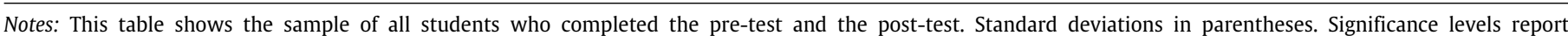

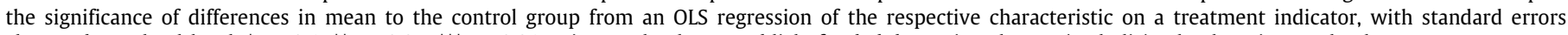

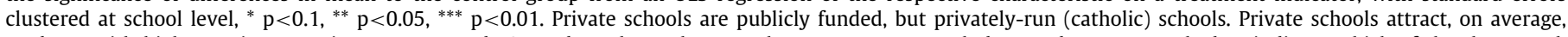

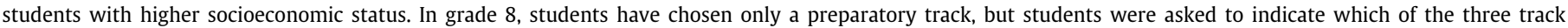

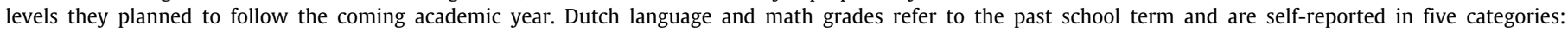

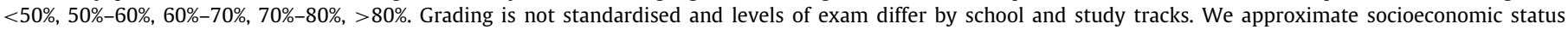

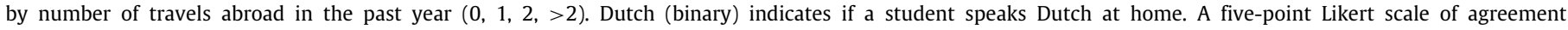

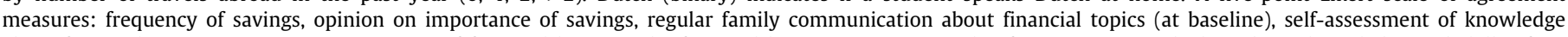

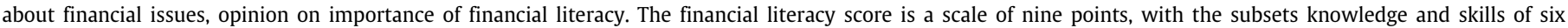
and three points, respectively.

\section{Descriptive statistics and baseline balance}

44 schools registered for participation and were randomly assigned to the four experimental groups. Figure A1 in the appendix shows the sample sizes by experimental group at the different stages of the experiment. After randomisation, 1944 students in 34 schools filled in the pre-test. Table A1 in the appendix shows the descriptive statistics of the sample at the pre-test, before the attrition that occurred during the intervention. It compares the means of the observable characteristics between the four experimental groups at baseline. Due to attrition after randomisation, but before the pre-test, there are some significant differences in student characteristics between the control group and each treatment group at baseline.

The final sample of students who filled in the pre-test and the post-test consists of 1253 students from 28 schools. The attrition rate hence amounted to $35.55 \%$. Compared to an ideal power of 337 students in each experimental group, the final sample is slightly underpowered, as the average size of the experimental groups amounts to $313.25 .^{3}$

Attrition is clustered at school, teacher and class level. As the implementation of the treatment was not in the hand of the

3 The power calculation is based on the formula which can be found in the registration of this experiment. For the computation, an effect size of 0.5 standard deviations, a conventional power of 0.8 and a significance level of 0.05 are used. The intracluster correlation of 0.1 and the average number of students per cluster of 44.75 are calculated from the sample. researchers, the attrition is driven by teachers who signed up for participation, but eventually did not find the time to implement the tests and schedule the intervention in their already busy curriculum, thus dropping out with all of their classes. Since the majority of schools signed up with one or two teachers, complete schools dropped out of the sample. Only a small share of the attrition is due to individual students from participating classes who were absent on the test day. As the Flemish education system is strongly segregated, the attrition of schools led to differences in observable characteristics between the experimental groups. Table A2 in the appendix shows the differences in student characteristics between compliers and non-compliers, i.e. the full sample at the pre-test and the sample of students who also filled in the post-test, for each experimental group. Despite a few significant differences, no systematic pattern becomes apparent between complying students and non-complying students in terms of their background characteristics at baseline.

Table 1 summarises the descriptive statistics of the final sample. In Flanders, schools are privately or publicly run, although both types of schools receive public funding. Private schools, the majority of which are catholic schools, are commonly perceived as attracting students with a higher socioeconomic status. As in all of Flanders, the majority of schools in the sample are private schools. In grade 9 , students are split into ability tracks, which are the academic track, the technical track and the vocational track. The academic track prepares students for academic higher education, whereas the technical and vocational tracks prepare for professional higher education or the labour market. In grade 
8, students already choose electives that prepare for a particular track, allowing us to assign a track to students in grade 8 . The majority of students in the sample follow the academic track, while students in the vocational track are underrepresented. As there are no standardised exams in Flanders, it should be noted that the language and mathematics grades in Table 1 are not fully comparable across classes and schools, since grading standards differ by schools and tracks.

Students in the sample are on average 13-14 years old and approximately half of the students are female. Due to the attrition, the final sample is not fully balanced on observable characteristics across the four experimental groups. In treatment group 1, language and mathematics grades and the mean socioeconomic status are significantly lower than in the control group. In treatment group 2, the mean socioeconomic status and the share of students speaking Dutch, i.e. the language of instruction, at home, are significantly lower than in the control group. In treatment group 3 , the mean language grade is significantly lower than in the control group.

The outcome variables are financial literacy, which was measured on nine questions about the course topic, and the two subsets of knowledge on six items and financial skills on three items (see Section 2). Financial literacy, as measured in the pre-test, is significantly lower in treatment groups 1 and 3. Before treatment, all three treatment groups perform on average significantly worse than the control group on financial skills. Baseline family communication with parents about the course topics, which was measured on a five-point Likert scale, is significantly lower in all treatment groups than in the control group.

Within the final sample, we observe non-compliance with the homework assignment in all treatment groups. Table A3 in the appendix shows the baseline characteristics of students who completed the homework assignment and students who did not complete the homework assignment in the final sample, by type of homework assignment, i.e. the homework assigned to the student alone (treatment 1 ) and the homework assigned to be completed together with a parent (treatment 2 and treatment 3). For both types of homework assignment, students who completed the assignment have significantly higher mathematics grades than students who did not complete the assignment. For the homework where parental involvement was prompted, there are more significant differences between compliers and non-compliers than for the homework assigned for students alone. In particular, non-compliers of the homework with parental involvement have significantly lower pre-test scores on financial literacy and a lower share of students speaking Dutch at home than those who completed the homework with stimulated parental involvement.

Table 2 shows the average homework scores of students and financial literacy scores of parents. The mean homework score is significantly higher in treatment group 2 than in treatment group 1 . As the average homework score is also higher in treatment group 3 than in treatment group 1, this likely indicates that the stimulation of parental involvement resulted in a parent helping with the homework. Parents' financial literacy does not differ significantly across treatment groups. Unfortunately, noncompliance among parents was very high. As parents could not be reached directly by the research team, the distribution of the parent questionnaire relied on the teachers and students to pass it on to parents and the incentive to participate was low for parents. In the final sample of students who filled in the pretest and the post-test, only $54 \%$ of parents completed the parent questionnaire. The parent scores are therefore not used in the analyses.

\section{Methodology}

Given the differences between experimental groups at baseline, the differences on learning outcomes could depend on observable and unobservable background characteristics rather than the intervention only. Therefore, intention-to-treat OLS regression which is usually employed for randomised experiments is likely to give biased estimates. ${ }^{4}$ To account for differences between the experimental groups at baseline and to identify the effects of treatment, we use a difference-in-differences (DiD) methodology. ${ }^{5}$ The underlying assumption of the DiD methodology is that, in the absence of treatment, the treatment groups follow the same trend as the control group. The stable unit value assumption holds if there are no cross-school spillovers, which is reasonable to assume in the given setting. The difference-indifferences approach is specified as follows:

$y_{i, j}=\alpha+\beta_{1} C+\beta_{2} P+\beta_{3} I+\gamma T+\delta_{1} C * T+\delta_{2} P * T+\delta_{3} I * T+\epsilon_{i, j}$

where $y_{i, j}$ denotes the learning outcome, i.e. the financial literacy score or the score on the subset of financial knowledge or financial skills which is regressed on the treatment and time dummies as well as the interaction of these. Exploiting the additive nature of the different treatments, $C$ stands for the classroom intervention which was assigned in all treatment groups, $P$ for the parental involvement stimulated through homework in treatment groups 2 and 3, and $I$ for the information intervention in treatment group 3. $T$ is a binary variable indicating time, where 0 is the baseline and 1 the post-test. The coefficients of the interaction terms identify the treatment effect of the classroom intervention $\left(\delta_{1}\right)$, the value added of the parental involvement measure $\left(\delta_{2}\right)$ and the value added of the information intervention $\left(\delta_{3}\right)$. The standard errors $\epsilon_{i, j}$ are clustered at school level, i.e. the level of treatment assignment.

In order to further balance the differences between treatment groups, in the main specification, we apply the difference-indifferences model in a matched sample. In this way, student characteristics in the treatment groups that might influence the learning curve during the intervention are balanced thanks to the matching. We use coarsened exact matching (CEM), following Blackwell et al. (2009). ${ }^{6}$ We match students of each treatment group, based on background characteristics collected at the pre-test, sequentially to the students in the control group and combine the matched observations to a matched sample. As school characteristic, only the type of school (private or public) and education track was available. Hence, we match students on the pre-test score, the type of school (private or not), the grade ( 8 or 9 ), the mathematics grade, the Dutch language grade, track (academic or not), gender, socioeconomic status and family communication at baseline. These variables were selected in order to maximise the balance in the matched sample in each step of matching, based on the $\mathcal{L}_{1}$ statistic (Blackwell et al., 2009). Table A4 in the appendix provides descriptive statistics of the matched sample and shows that, after matching, the experimental groups are well balanced on the observable student characteristics measured at the pre-test.

\footnotetext{
4 Table B1 in the appendix shows that the estimates of treatment effects differ widely between an OLS intention-to-treat specification without control variables and the corresponding specification which includes a set of baseline characteristics of students as control variables. This indicates that the background characteristics clearly influence the results, such that we cannot assume that unobserved characteristics are balanced across the experimental groups.

5 While RCT data are commonly evaluated using intention-to-treat OLS regression models, earlier research shows that in case of unbalanced data and high autocorrelation (which is, given the use of pre-test scores, clearly the case in our study), a DiD model is more appropriate (e.g. Hidrobo et al., 2014; McKenzie, 2012; Murnane and Willett, 2010; Slemrod et al., 2001).

6 A growing body of literature suggests that coarsened exact matching has interesting properties in comparison to other matching methodologies (e.g. Amusa et al., 2019; Bertoni et al., 2020; King and Nielsen, 2019).
} 
Table 2

Homework and parent scores.

\begin{tabular}{|c|c|c|c|c|}
\hline \multirow[b]{3}{*}{ Homework Score $(/ 5)$} & \multirow{2}{*}{$\begin{array}{l}\text { Treatment } 1 \\
\text { Class }\end{array}$} & \multirow{2}{*}{$\frac{\text { Treatment } 2}{T 1+\text { Parental Involvement }}$} & \multicolumn{2}{|l|}{ Treatment 3} \\
\hline & & & T2 + Parental Information & $N$ \\
\hline & $(1.271)$ & $4.036^{* * *}$ & $(1.270)$ & 479 \\
\hline Parent Score $(/ 6)$ & $(1.787)$ & $(1.733)$ & $(1.851)$ & 513 \\
\hline
\end{tabular}

Notes: Standard deviations in parentheses. Significance levels report differences to treatment group 1 ('class') from an OLS regression with standard errors clustered at school level, ${ }^{*} \mathrm{p}<0.1,{ }^{* *} \mathrm{p}<0.05,{ }^{* * *} \mathrm{p}<0.01$. Students in the control group did not receive any homework or parent questionnaires.

\section{Results}

The results of the difference-in-differences specification in the matched sample are presented in Section 6.1. To account for the non-compliance with the homework assignment, Section 6.2 presents the effect for students who complied with the homework assignment.

\subsection{Intention-to-treat effect}

Table 3 shows the results of the difference-in-differences estimation in the matched sample for the three learning outcomes, i.e. the financial literacy score and its two components of knowledge and skills. The classroom intervention has a significant positive effect on all three outcome variables. Receiving the classroom intervention improves financial literacy by 0.53 standard deviations compared to the control group. Stimulating parental involvement in the homework improves scores by 0.05 standard deviations in addition to the classroom intervention, although this estimate is not significantly different from zero. Providing parents information in addition to the stimulation of parental involvement in the homework does not lead to any additional increases in financial literacy, as the coefficient of 0.01 standard deviations is small and insignificant. These results suggest that, despite common practice in many schools, providing parents with additional information does not significantly improve students' immediate learning outcomes. The F-Tests in the bottom panel of Table 3 show that students in each treatment group perform significantly better on financial literacy than students in the control group, regardless of parental involvement and information measures being added or not.

The result is similar on the subset of financial knowledge questions, where all treatment groups perform significantly better than the control group and the value added of parental involvement and information provision is not significant.

On the subset of financial skills, the effect of the classroom intervention is also positive and significant. With 0.16 standard deviations, it is smaller than the effect on knowledge. As for knowledge, the value added of parental involvement is not significant. However, the positive value added of information on financial skills compared to parental involvement as well as compared to only receiving a classroom intervention is statistically significant. Since parental involvement has a small negative coefficient on financial skills, this means that the parental involvement component has only a significant effect on financial skills if, in addition, information is provided to parents.

The results thus reveal that the intervention is effective in improving learning outcomes of students, but adding parental involvement measures does not provide significant value added. The information intervention only provides value added on financial skills, yet not on financial knowledge. The results remain robust when looking at different subsamples as we do not find strong heterogeneous treatment effects based on student characteristics at baseline. Tables B2 and B3 in the appendix show the heterogeneous effects for relevant student characteristics, on which heterogeneous effects could have been expected. Particularly surprising is the fact that we do not find clear evidence of heterogeneous effects with respect to the socioeconomic status of students. Although the financial skills of high socioeconomic status students seem to benefit from the information provision to their parents, the observed effect is only significant at the $10 \%$-level.

\subsection{Compliance with the homework assignment}

The data collected from the digital homework assignment allows us to observe students' compliance with this task. For all treatment groups, we observe if a student completed the homework assignment in the online form. However, it could not be observed if the parents were involved or effectively received the information, such that the results presented in this section account for the compliance with the homework assignment, but only show the intention-to-treat with parental involvement and information.

Table 4 shows the results of a difference-in-differences regression using the matched sample and treatment indicators that reflect compliance with the homework assignment. In particular, the first coefficient represents the average treatment effect on the treated compared to the control group of all students who received the class, but no other elements of the intervention. That means that this coefficient shows the effect for students of all three treatment groups who did not complete their homework assignment. This effect is positive and significant on financial literacy and financial knowledge, but not on financial skills. The second coefficient represents the average treatment effect on the treated of completing any type of homework assignment, compared to those students who only followed the class without doing their homework. This effect of completing the preparatory homework is positive but statistically not significant on all three outcome variables. We hence cannot confirm any value added of completing a preparatory homework assignment in addition to following the classroom intervention at school.

The third coefficient displays the average treatment effect on the treated for students who completed the homework in which parental involvement was prompted. While it was recorded whether the student completed the homework, it could not be observed if the parents were actually involved. The effect in Table 4 thus reflects the compliance with the homework assignment, but only the intention-to-treat with parental involvement. The effect of stimulating parental involvement is small and negative, yet, not significant. This means that there is no significant value added of prompting parental involvement in homework.

The last coefficient shows the intention-to-treat effect for those students who were assigned to receiving information for their parents. In line with the ITT results presented in the previous section, the estimate for the added value of information provision to parents is only significant on financial skills. On financial literacy and financial knowledge, the effect is small and statistically not significant. On financial skills, information provision significantly improves student outcomes compared to stimulating parental involvement without information provision. However, compared to the classroom intervention with homework without stimulated parental involvement, the value added is statistically not significant. 
Table 3

Intention-to-treat effect in the matched sample.

\begin{tabular}{llll}
\hline & Financial literacy & Financial knowledge & Financial skills \\
\hline Class & $0.528^{* *}$ & $0.590^{* *}$ & $0.163^{* *}$ \\
T1 + Parental Involvement & $(0.190)$ & $(0.214)$ & $(0.075)$ \\
& 0.048 & 0.106 & -0.055 \\
T2 + Parental Information & $(0.202)$ & $(0.256)$ & $(0.102)$ \\
& 0.007 & -0.164 & $0.228^{* *}$ \\
\hline Class vs. Control & $(0.110)$ & $(0.175)$ & $(0.104)$ \\
T1 + Par. Inv. vs. Control & 0.011 & 0.011 & 0.040 \\
T2 + Par. Info. vs. Control & 0.000 & 0.000 & 0.251 \\
T1 + Par. Inv. vs. Class & 0.000 & 0.000 & 0.000 \\
T2 + Par. Info. vs. Class & 0.815 & 0.683 & 0.598 \\
T2 + Par. Info. vs. T1 + Par. Inv. & 0.779 & 0.801 & 0.062 \\
\hline R-squared & 0.952 & 0.358 & 0.038 \\
$\mathrm{~N}$ & 0.069 & 0.122 & 0.008 \\
\hline
\end{tabular}

Notes: Difference-in-differences regression using the matched sample. Observations were matched using Coarsened Exact Matching on the pre-test score, type of school (private or not), grade (8 or 9), mathematics grade, Dutch language grade, track (academic or not), gender, socioeconomic status and family communication at baseline. Reference category: control group. Standard errors clustered at school level in parentheses. Bottom panel shows p-values of F-test for equality of coefficients. ${ }^{*} \mathrm{p}<0.10,{ }^{* *} \mathrm{p}<0.05,{ }^{* * *}$ $\mathrm{p}<0.01$.

Table 4

Average treatment effect on the treated.

\begin{tabular}{llll}
\hline & Financial literacy & Financial knowledge & Financial skills \\
\hline Class & $0.420^{* *}$ & $0.487^{* *}$ & 0.108 \\
& $(0.179)$ & $(0.197)$ & $(0.083)$ \\
Class + Homework & 0.311 & 0.356 & 0.085 \\
& $(0.198)$ & $(0.211)$ & $(0.103)$ \\
T1 + Parental Involvement & -0.116 & -0.152 & $(0.007$ \\
& $(0.171)$ & $(0.210)$ & $0.178^{*}$ \\
T2 + Parental Information & 0.035 & -0.087 & $(0.101)$ \\
& $(0.148)$ & $(0.203)$ & 0.206 \\
Class vs. Control & 0.027 & 0.021 & 0.024 \\
Class + Homework vs. Control & 0.000 & 0.000 & 0.129 \\
T1 + Par. Inv. vs. Control & 0.000 & 0.002 & 0.001 \\
T2 + Par. Info. vs. Control & 0.000 & 0.000 & 0.417 \\
Class + Homework vs. Class & 0.130 & 0.103 & 0.511 \\
T1 + Par. Inv. vs. Class & 0.209 & 0.292 & 0.048 \\
T2 + Par. Info. vs. Class & 0.284 & 0.603 & 0.958 \\
T1 + Par. Inv. vs. Class + Homework & 0.503 & 0.477 & 0.125 \\
T2 + Par. Info. vs. Class + Homework & 0.499 & 0.050 & 0.090 \\
T2 + Par. Info. vs. T1 + Par. Inv. & 0.813 & 0.673 & 0.019 \\
\hline R-squared & 0.082 & 0.128 & 1560 \\
N & 1560 & 1560 & \\
\hline
\end{tabular}

Notes: Difference-in-differences regression using the matched sample. The coefficients of the Homework treatment and the Parental Involvement treatment reflect the effect for compliers with the homework assignment. Students from treatment groups 2 and 3 who did not complete the homework are included in the first group of classroom intervention only. Observations were matched using Coarsened Exact Matching on the pre-test score, type of school (private or not), grade (8 or 9), mathematics grade, Dutch language grade, track (academic or not), gender, socioeconomic status and family communication at baseline. Reference category: control group. Standard errors clustered at school level in parentheses. Bottom panel shows p-values of F-test for equality of coefficients. ${ }^{*} \mathrm{p}<$ $0.10,{ }^{* *} \mathrm{p}<0.05,{ }^{* * *} \mathrm{p}<0.01$.

These results should be interpreted with caution, since compliance with the homework assignment is likely to be endogenous. In particular, table $A 3$ in the appendix shows that the compliers and non-compliers of the homework assignment are not balanced in terms of student characteristics at baseline. However, approaches that take endogeneity into account, such as instrumental variable regression, are not compatible with the difference-in-differences approach. Instrumental variable regression, run on the matched sample, yields overall similar results for information on financial skills (see table B4 in the appendix). This specifications differs in some estimates, such as the contrasting result of a significant negative effect of information provision on knowledge, which is likely caused by the differences in baseline characteristics, which are equalised by the use of the difference-in-differences specification in the main analysis. Table B5 in the appendix shows that similar results are also obtained when applying the instrumental variable regression to the first differences of the outcome in order to approximate the difference-in-differences setting, as done by Oosterbeek et al, (2010). The significant positive effect on financial skills is retained in this specification as well. Yet, the value added of the information treatment on financial knowledge is again negative and significant. While this specification takes the differences in the outcome variable found at baseline into account, it still disregards the differences on other student characteristics, which are captured in the difference-in-differences approach.

\section{Discussion and conclusion}

Information provision to parents represents a scalable lowcost intervention to increase parental involvement in education. This study shows, based on a randomised controlled trial with 
1253 students from grade 8 and 9 in Flanders, that a financial education class with stimulation of parental involvement and provision of information to parents effectively improves students' financial literacy. However, the added value of providing parents subject-related information is not significant in the dimensions of financial literacy and financial knowledge. On the aspects of the course topic relating to financial skills, we find that information provision to parents can significantly increase learning outcomes. Stimulating parental involvement in a homework assignment did not provide significant value added on any of the learning outcomes.

Our findings are in line with previous experiments in financial education that show the overall effectiveness of financial education at school together with a parental involvement element (Bruhn et al., 2016; Sherraden et al., 2011; Maldonado et al., 2021). We further confirm the finding of Maldonado et al. (2021) that adding parental involvement in homework to a financial education class does not significantly improve average financial literacy. Similar to (Maldonado et al., 2021), who find parental involvement in homework to matter for disadvantaged students in the behavioural dimension, our findings for information provision show the relevance of parents for financial skills. Indeed, it seems plausible that parents can have a larger impact on those aspects of their children's education which relate to a family's everyday life. This is clearly the case for financial skills, but could be equally relevant in other disciplines, such as health and nutrition, media literacy or safe online behaviour.

Yet, our results suggest that there is no added value of providing parents information for improving students' knowledge. As the necessary statistical power to detect an effect is given in the large sample, it is possible that the treatment was not powerful enough if not all parents received the information brochure. Nevertheless, the treatment is realistic, since scalable information interventions that rely on teachers and students to forward information to parents are likely resulting in similar non-compliance in reality. Although the research team was responsible for the design and evaluation phase of the experiment, the practical implementation of the intervention was in the hands of teachers. This makes sure that our estimates are not necessarily upper bound estimates of an intervention with perfect implementation. In other words, this study design simulates the implementation of interventions in the real world, with the disadvantage of a lower degree of control over compliance with the treatment and the tests. Testing scalable interventions in realistic conditions is important to evaluate the effects of potential policies.

The findings have hence relevant policy implications, since information provision to parents can serve as a low-cost largescale intervention which can easily be implemented by schools or the government to promote desirable skills of citizens at a young age. This study shows that information provision to parents does not necessarily improve knowledge, but can be used to improve skills in subjects that teach students general competences relevant for daily life. It is possible that, in order to improve students' knowledge, information for parents needs to be complemented with a different additional intervention, such as a parent event. Future research should explore measures to increase and measure compliance in information interventions.

\section{CRediT authorship contribution statement}

Joana Elisa Maldonado: Conceptualization, Formal analysis, Investigation, Writing - original draft. Kristof De Witte: Conceptualization, Writing - review \& editing, Project administration, Supervision, Funding acquisition.

\section{Declaration of competing interest}

The authors declare that they have no known competing financial interests or personal relationships that could have appeared to influence the work reported in this paper.

\section{Acknowledgements}

The authors are grateful to Koen Declercq, Geert Van Campenhout, Lieve Lammens, Johan Mestdagh, Els Lagrou, Danièle Van der Espt, Tim Kaiser and conference participants in Leuven for their helpful comments and suggestions.

\section{Funding}

This work was supported by the Research Foundation Flanders (FWO) (grant number S000617N).

\section{Appendix A. Supplementary data}

Supplementary material related to this article can be found online at https://doi.org/10.1016/j.jbef.2021.100548.

\section{References}

Amusa, L., Zewotir, T., North, D., 2019. Evaluation of subset matching methods: Evidence from a Monte Carlo simulation study. Am. J. Appl. Sci. 16 (3), http://dx.doi.org/10.3844/ajassp.2019.92.100.

Avvisati, F., Gurgand, M., Guyon, N., Maurin, E., 2014. Getting parents involved: A field experiment in deprived schools. Rev. Econ. Stud. 81 (1), 57-83. http://dx.doi.org/10.1093/restud/rdt027.

Becchetti, L., Caiazza, S., Coviello, D., 2013. Financial education and investment attitudes in high schools: evidence from a randomized experiment. Appl. Financ. Econ. 23 (10), 817-836. http://dx.doi.org/10.1080/09603107.2013. 767977.

Bergman, P., 2021. Parent-child information frictions and human capital investment: Evidence from a field experiment. J. Polit. Econ. 129 (1), 286-322.

Bergman, P., Chan, E.W., 2021. Leveraging parents through low-cost technology: The impact of high-frequency information on student achievement. J. Hum. Resour. 56 (1), 125-158. http://dx.doi.org/10.3368/jhr.56.1.1118-9837R1.

Berlinski, S., Busso, M., Dinkelman, T., Martínez A., C., 2021. Reducing ParentSchool Information Gaps and Improving Education Outcomes: Evidence From High-Frequency Text Messages. NBER Work. Pap. Ser. 28581.

Bertoni, D., Curzi, D., Aletti, G., Olper, A., 2020. Estimating the effects of agri-environmental measures using difference-in-difference coarsened exact matching. Food Policy 90 (101790), http://dx.doi.org/10.1016/j.foodpol.2019. 101790.

Blackwell, M., Iacus, S., King, G., Porro, G., 2009. cem: Coarsened exact matching in Stata. Stata J. 9 (4), 524-546.

Bover, O., Hospido, L., Villanueva, E., 2018. The Impact of High School Financial Education on Financial Knowledge and Choices: Evidence from a Randomized Trial in Spain. IZA Discuss. Pap. Ser. 11265.

Bruhn, M., de Souza Leão, L., Legovini, A., Marchetti, R., Zia, B., 2016. The impact of high school financial education: Evidence from a large-scale evaluation in Brazil. Am. Econ. J. Appl. Econ. 8 (4), 256-295. http://dx.doi.org/10.1257/ app.20150149.

Bucciol, A., Veronesi, M., 2014. Teaching children to save: What is the best strategy for lifetime savings? J. Econ. Psychol. 45, 1-17. http://dx.doi.org/ 10.1016/j.joep.2014.07.003.

Compen, B., De Witte, K., Schelfhout, W., 2021. The impact of teacher engagement in an interactive webinar series on the effectiveness of financial literacy education. Br. J. Educ. Technol. (ISSN: 14678535) 52 (1), 411-425. http://dx.doi.org/10.1111/bjet.13013.

De Beckker, K., De Witte, K., Van Campenhout, G., 2019. Identifying financially illiterate groups: An international comparison. Int. J. Consum. Stud. 43 (5), 490-501. http://dx.doi.org/10.1111/ijcs.12534.

De Beckker, K., De Witte, K., Van Campenhout, G., 2021. The effect of financial education on students' consumer choices: Evidence from a randomized experiment. J. Econ. Behav. Organ. 188, 490-501.

Dizon-Ross, R., 2019. Parents' beliefs about their children's academic ability: Implications for educational investments. Amer. Econ. Rev. 109 (8), 2728-2765. http://dx.doi.org/10.1257/aer.20171172.

Dohmen, T., Falk, A., Huffman, D., Sunde, U., 2012. The intergenerational transmission of risk and trust attitudes. Rev. Econ. Stud. 79, 645-677. http: //dx.doi.org/10.1093/restud/rdr027. 
Doss, C., Fahle, E.M., Loeb, S., York, B.N., 2019. More than just a nudge: Supporting kindergarten parents with differentiated and personalized text messages. J. Hum. Resour. 54 (3), 567-603. http://dx.doi.org/10.3368/jhr.54. 3.0317-8637R

Grohmann, A., Kouwenberg, R., Menkhoff, L., 2015. Childhood roots of financial literacy. J. Econ. Psychol. 51, 114-133. http://dx.doi.org/10.1016/j.joep.2015. 09.002.

Hanson, T.A., Olson, P.M., 2018. Financial literacy and family communication patterns. J. Behav. Exp. Financ. 19, 64-71. http://dx.doi.org/10.1016/j.jbef. 2018.05.001.

Heddy, B.C., Sinatra, G.M., 2017. Transformative parents: Facilitating transformative experiences and interest with a parent involvement intervention. Sci. Educ. 101 (5), 765-786. http://dx.doi.org/10.1002/sce.21292.

Hidrobo, M., Hoddinott, J., Peterman, A., Margolies, A., Moreira, V., 2014. Cash, food, or vouchers? Evidence from a randomized experiment in northern ecuador. J. Dev. Econ. 107, 144-156. http://dx.doi.org/10.1016/j.jdeveco.2013. 11.009 .

Iterbeke, K., De Witte, K., Declercq, K., Schelfhout, W., 2020. The effect of ability matching and differentiated instruction in financial literacy education. Evidence from two randomised control trials. Econ. Educ. Rev. 78, http: //dx.doi.org/10.1016/j.econedurev.2019.101949.

Iterbeke, K., De Witte, K., Schelfhout, W., 2021. The effects of computerassisted adaptive instruction and elaborated feedback on learning outcomes. A randomized control trial. Comput. Human Behav. 120 (106666), http: //dx.doi.org/10.1016/j.chb.2020.106666.

Kaiser, T., Lusardi, A., Menkhoff, L., Urban, C.J., 2020. Financial Education Affects Financial Knowledge and Downstream Behaviors. NBER Work. Pap. Ser. 27057.

Kaiser, T., Menkhoff, L., 2020. Financial education in schools: A meta-analysis of experimental studies. Econ. Educ. Rev. 78, http://dx.doi.org/10.1016/j. econedurev.2019.101930.

King, G., Nielsen, R., 2019. Why propensity scores should not be used for matching. Polit. Anal. 27 (4).

Lieberman, E.S., Posner, D.N., Tsai, L.L., 2014. Does information lead to more active citizenship? Evidence from an education intervention in Rural Kenya. World Dev. 60, 69-83. http://dx.doi.org/10.1016/j.worlddev.2014.03.014.

Lührmann, M., Serra-Garcia, M., Winter, J., 2018. The impact of financial education on adolescents' intertemporal choices. Am. Econ. J. Econ. Policy 10 (3), 309-332. http://dx.doi.org/10.1257/pol.20170012.

Lusardi, A., Mitchell, O., Curto, V., 2010. Financial literacy among the Young. J. Consum. Aff. 44 (2), 358-380. http://dx.doi.org/10.1111/j.1745-6606.2010. 01173.x.

Maldonado, J.E., De Witte, K., Declercq, K., 2021. The effects of parental involvement in homework: two randomised controlled trials in financial education. Empir. Econ. in print, http://dx.doi.org/10.1007/s00181-021-02058-8.

Mayer, S.E., Kalil, A., Oreopoulos, P., Gallegos, S., 2019. Using behavioral insights to increase parental engagement: The parents and children together intervention. J. Hum. Resour. 54 (4), 900-925. http://dx.doi.org/10.3368/jhr.54.4. 0617.8835R.

McKenzie, D., 2012. Beyond baseline and follow-up: The case for more $\mathrm{T}$ in experiments. J. Dev. Econ. 99, 210-221. http://dx.doi.org/10.1016/j.jdeveco. 2012.01.002.
Moreno-Herrero, D., Salas-Velasco, M., Sánchez-Campillo, J., 2018. Factors that influence the level of financial literacy among young people: The role of parental engagement and students' experiences with money matters. Child. Youth Serv. Rev. 95 (June), 334-351. http://dx.doi.org/10.1016/j.childyouth. 2018.10.042.

Murnane, R.J., Willett, J.B., 2010. Methods Matter: Improving Causal Inference in Educational and Social Science Research. Oxford University Press, ISBN: 9780199753864.

OECD, 2014. PISA 2012 Results: Students and Money: Financial Literacy Skills for the 21st Century (Volume VI). Technical Report, OECD, http://dx.doi.org/ $10.1787 / 9789264208094$-en.

OECD, 2016. Adult Financial Literacy Competencies. Technical Report, OECD, Paris, p. 95.

OECD, 2017. PISA 2015 Results (Volume IV): Students' Financial Literacy. Technical Report, OECD, Paris, http://dx.doi.org/10.1787/9789264270282-en.

Oosterbeek, H., van Praag, M., Ijsselstein, A., 2010. The impact of entrepreneurship education on entrepreneurship skills and motivation. Eur. Econ. Rev. 54 442-454. http://dx.doi.org/10.1016/j.euroecorev.2009.08.002.

Rozek, C.S., Svoboda, R.C., Harackiewicz, J.M., Hulleman, C.S., Hyde, J.S., 2017. Utility-value intervention with parents increases students' STEM preparation and career pursuit. Proc. Natl. Acad. Sci. USA 114 (5), 909-914. http://dx.doi. org/10.1073/pnas.1607386114.

Sherraden, M.S., Johnson, L., Guo, B., Elliott, W., 2011. Financial capability in children: Effects of participation in a school-based financial education and savings program. J. Fam. Econ. Issues 32, 385-399. http://dx.doi.org/10.1007/ s10834-010-9220-5.

Shim, S., Serido, J., Tang, C., Card, N., 2015. Socialization processes and pathways to healthy financial development for emerging young adults. J. Appl. Dev. Psychol. 38, 29-38. http://dx.doi.org/10.1016/j.appdev.2015.01.002.

Slemrod, J., Blumenthal, M., Christian, C., 2001. Taxpayer response to an increased probability of audit: Evidence from a controlled experiment in Minnesota. J. Publ. Econ. 79 (3), 455-483. http://dx.doi.org/10.1016/S00472727(99)00107-3.

Van Campenhout, G., 2015. Revaluing the role of parents as financial socialization agents in youth financial literacy programs. J. Consum. Aff. 49 (1), 186-222. http://dx.doi.org/10.1111/joca.12064.

Webley, P., Nyhus, E.K., 2006. Parents' influence on children's future orientation and saving. J. Econ. Psychol. 27, 140-164. http://dx.doi.org/10.1016/j.joep. 2005.06.016.

York, B.N., Loeb, S., Doss, C., 2019. One step at a time: The effects of an early literacy text-messaging program for parents of preschoolers. J. Hum. Resour. 54 (3), 537-566. http://dx.doi.org/10.3368/jhr.54.3.0517-8756R. 